Huerta, Ricard.

Profesor Titular de la Universitat de València, Grupo CREARI de Investigación en Pedagogías Culturales (GIUV2013-103), Institut de Creativitat i Innovacions Educatives, Departament de Didàctica de l'Expressió Musical, Plástica i Corporal. Facultat de Magisteri.

\title{
El proyecto artístico Mujeres Maestras en Perú, Colombia y Ecuador.
}

\section{Women Teacher Art Project in Peru, Colombia and Ecuador.}

TIPO DE TRABAJO:

Comunicación.

PALABRAS CLAVE:

Artes visuales, Educación, Educación artística, Museos, Identidades.

KEY WORDS:

Visual Arts, Education, Art Education, Museums, Identities.

\section{RESUMEN.}

El proyecto "Mujeres Maestras" es un homenaje a las docentes que acerca la educación en artes a la investigación artística. Esta indagación se propone a partir de la creación artística, implicando a profesorado y alumnado de centros educativos, al tiempo que se gestiona y plantea la ubicación de las muestras en museos y salas de arte de todo el mundo. En 2017 la muestra visita Medellín (Colombia) y Lima (Perú). Para 2018 está previsto exponerla en Cuenca (Ecuador). Cada exposición de Mujeres Maestras la componen 21 obras que son realizadas en exclusiva para el país y museo o centro de arte en el que se organiza la muestra. El grafismo y la poética de los gestos acompañan al homenaje que el autor rinde a estas mujeres que representan a un colectivo tan importante y al que se siente fuertemente vinculado, debido a su trayectoria durante más de tres décadas como profesor de Educación Artística. Además del trabajo del artista también se expone un mural con dibujos del alumnado de los colegios que colaboran. Las aportaciones de estos niños y niñas se completa con la mirada de las propias maestras a través de un audiovisual en el que oímos sus reflexiones personales, sus ideas acerca del trabajo, la realidad educativa en la que viven, y las situaciones a las que deben hacer frente cada día, lo cual visibiliza la realidad de este colectivo tan poco valorado. La investigación se posiciona a nivel internacional imbricando perspectivas de ámbitos geográficos diferentes. El proyecto acerca al terreno artístico una realidad social, cultural y especialmente educativa: Entre los profesionales de la docencia la mayoría son mujeres. Estamos tratando una cuestión de identidad. La iniciativa también está animando a las maestras a generar nuevos parámetros y usos de la educación artística en la escuela.

\section{ABSTRACT}

Mujeres Maestras (Women Teacher Project) is a tribute to the teachers who bring Art Education to the Arts-Based Research. We propose this inquiry from the art creation, involving teachers and students of educational centers. Through this work in progress we manage the future location of exhibitions in museums and art centers around the world. This year the exhibition visits Medellín (Colombia) and Lima (Peru). The next year planned to exhibit in Cuenca (Ecuador). Each exhibition of Mujeres Maestras consists of 21 works made exclusively for the museum or art center in which the show is organized. The graphics and the poetics of the gestures are part of the homage that the author gives to these women who represent a very important collective. The author feels strongly linked due to his trajectory during more than three decades as professor of Art Education. In addition to the artist's work is also exhibited drawings of the students of the 
schools. The contributions of these children completed with the eyes of the teachers themselves through a video in which we hear their personal reflections, their ideas about the work, the educational reality in which they live, and the situations they are every day. The reality of this teachers' group is so little valued. The research positioned at an international level with perspectives from different geographical areas. The Project incorporates a social, cultural and especially educational reality into the artistic field: Among the teaching professionals, the majority are women. We are dealing with a question of identity. The initiative is also encouraging teachers to generate new parameters and uses of art education in Primary School.

\section{CONTENIDO.}

\section{Introducción.}

Acercar las innovaciones artísticas al terreno de la Educación Primaria sigue resultando complicado, teniendo en cuenta que en este entorno de educación formal existen numerosos elementos que continúan vinculando la práctica de las artes al concepto tradicional del artista genio o a la manipulación de materiales en base a talleres participativos. No es nuestra intención eliminar este tipo de prácticas, que deberían evolucionar hacia posicionamientos mucho más porosos y plurales. Sin embargo, está en nuestro ánimo la idea de incorporar nuevas prácticas e introducir visiones artísticas innovadoras en las que se puedan sentir partícipes tanto el alumnado como el profesorado de Educación Primaria. Una de estas propuestas es el Proyecto Mujeres Maestras.

El proyecto se inició en 2005 al concretar la reflexión sobre la importancia que adquieren en nuestras vidas las mujeres de las que aprendemos, especialmente cuando se trata de maestras de Educación Primaria. Debido a mi profesión como docente e investigador universitario centrado en la Educación Artística, y teniendo en cuenta que la mayoría de mi alumnado son mujeres, consideré sumamente interesante investigar sobre la identidad de dicho colectivo. Así nació el proyecto, indagando sobre qué y quiénes son las mujeres docentes (especialmente las que trabajan en los colegios de primaria). La investigación combina formatos diferentes. Por un lado están las exposiciones en centros de arte, y por otro las publicaciones sobre la temática, tanto en formato libro (Huerta 2012) como mediante artículos en revistas (Huerta 2010, Huerta 2016), e incluso participando en congresos y reuniones científicas.

Hemos aplicado a nuestras investigaciones un modelo de metodología mixta que introduce aspectos combinados que provienen de paradigmas relacionados con la Educación Artística, con elementos que son propios de esta disciplina, como la Cultura Visual y las Historias de Vida (Rivas, Hernández, Sancho y Núñez, 2012). En cada una de las fases de la investigación queda más acentuada una de dichas metodologías. De este modo, cuando preparamos las entrevistas con las maestras resulta muy adecuado elaborar un procedimiento centrado en las Narrativas Personales. Pedimos a las maestras que nos relaten sus experiencias, cómo afrontan su trabajo cotidiano, qué aspectos positivos y negativos destacarían de la experiencia como docentes. Incluso les pedimos que nos hablen de su relación con las artes, de qué modo incorporan la actividad artística en sus tareas educativas, y cómo ha sido su formación en materia de artes. Las entrevistas planteadas como narrativas personales dentro del esquema de las Historias de Vida permiten acercarnos de manera personal a la realidad de las personas con quienes llegamos a establecer contacto directo. Al conocer personalmente a estas docentes nos adentramos en sus biografías, lo cual nos permitirá posteriormente interpretarlas desde la perspectiva de las artes, en tanto que representación gráfica y artefacto visual. Otro aspecto relevante de la investigación lo constituye la recogida de dibujos infantiles en los cuales el alumnado de primaria ha interpretado a sus respectivas maestras. Mediante estos trabajos, y a través de los mecanismos de análisis que proporciona la Cultura Visual, nos adentramos en los significados que ofrecen los trabajos infantiles, lo cual permite realizar un estudio cualitativo de los dibujos recogidos.

\section{Las exposiciones del proyecto Mujeres Maestras.}

En cada exposición del Proyecto Mujeres Maestras se pretende generar un acercamiento al mundo de las docentes, a sus identidades, a sus inquietudes, desde diferentes puntos de vista. Se trata de agrupar y combinar diferentes miradas: la mirada del artista, la mirada del alumnado, y la opinión de las propias maestras. En este último apartado, las docentes explican su propia visión del mundo, la forma en que se involucran, explicando mediante entrevistas grabadas en video sus motivos y las razones que les impulsan a llevar a cabo su propia tarea docente. La exposición está formada por tres espacios que se combinan e implementan. Se trata de tres miradas a la mujer maestra, a las mujeres maestras. Se intercalan tres perspectivas diferentes: la del artista, la del alumnado, y la de las propias protagonistas, las maestras. Distribuimos dichas perspectivas en lo que serían tres espacios interconectados, que se combinan en cada nueva exposición, adaptando aspectos en función del lugar en el que se realizará la muestra. Resultará fundamental la participación de los colegios que colaboran con la sala de exposiciones o el museo en el que se llevará a cabo la muestra. Nos detenemos seguidamente en cada uno de los tres espacios. 
El Espacio 1 representa la mirada del artista. Cómo observa y de qué modo interpreta el artista a las mujeres de quienes ha aprendido y continúa aprendiendo. Se trata de un homenaje que se plasma en dibujos, fotografías y pinturas. La mirada del artista que reflexiona sobre las mujeres maestras aportando una perspectiva desde la creación plástica, desde las artes visuales. Dibujos sobre papel o pinturas sobre lienzo, obras dedicadas a mujeres que nos han aportado sus ideas a través de las tareas docentes. Se realiza una serie de 21 piezas. Cada una de estas obras representa a una de las maestras entrevistadas. Se han realizado varias series, cada una pensada para un país, pero también elaborando un discurso curatorial ya que se piensa el formato y las características de las obras en función del espacio expositivo. Las sucesivas series toman como título el entorno geográfico al cual representan: Mujeres Maestras de Chile, Mujeres Maestras de Uruguay, Mujeres Maestras de Cuba, Mujeres Maestras del Perú, Mujeres Maestras de Colombia, Mujeres Maestras de Ecuador.

El espacio 2 representa la mirada del alumnado. ¿De qué modo ven y cómo interpretan los niños y las niñas de primaria a sus maestras? El espacio es una instalación basada en los dibujos de los niños y las niñas de los centros educativos próximos al lugar donde se realiza la exposición, jóvenes que dibujan y pintan a sus maestras. En este espacio la exposición cambia radicalmente, en función del lugar donde está previsto realizar la muestra, ya que los trabajos del alumnado provienen de los de los colegios vecinos o no muy alejados del lugar donde se montará la muestra. De esta manera la exposición Mujeres Maestras participa tanto del trabajo individual del artista como de las aportaciones de los escolares que han interpretado, también, a sus maestras. Se trata de una experiencia novedosa, ya que las maestras nos comentan que ellas nunca se habían sentido "modelos", es decir, que nunca habías posado ante su alumnado. Este tipo de iniciativas que promovemos también están animando a las maestras a generar nuevos parámetros y usos de la educación artística en la escuela. Los familiares del alumnado participante acuden a la muestra con el interés añadido que se ha generado por la participación activa en la exposición de sus hijos, nietos o sobrinos. Esta novedad permite acercar al espacio expositivo a un tipo de público que habitualmente no frecuenta las galerías de arte o los museos.

El espacio 3 está dedicado a la mirada de las propias maestras. ¿Cómo se ven? ¿Cómo les gustaría ser vistas? Se trata de dar un paso más para intentar conocer cómo se ven y cómo se interpretan las propias maestras, definiéndose a sí mismas. Esta tercera aportación relata en imágenes de qué modo se ven como maestras, como personas y como ciudadanas. En cada país entrevistamos a veintiuna mujeres maestras. Se graban en vídeo las entrevistas y posteriormente se edita un documental audiovisual con sus aportaciones. Estas maestras ofrecen una mirada que han proyectado sobre ellas mismas. De las entrevistadas, cada grupo de mujeres representa a un país. Se ha elaborado un discurso que intenta encajar en imágenes y sonidos la mirada que proyecta el individuo sobre sí mismo, pero también la idea de pertenencia a un cuerpo más amplio, en este caso al colectivo de las educadoras (al colectivo docente, muy feminizado en espacios como la educación infantil o la educación primaria). Se trata de estimular los rasgos identitarios vistos desde el propio colectivo. La instalación de este tercer espacio necesita una pantalla de proyección en la que va pasando el metraje del vídeo. En la pantalla aparecen las intervenciones de las maestras a quienes hemos entrevistado, asumiendo su papel en las tareas culturales, tanto a nivel profesional como personal. Hablan sobre ellas, y sobre la formación de su alumnado, testimoniando el entorno social en el que se desenvuelve su vida. El video actúa como un verdadero espacio geográfico, también frontera de unión y de vinculaciones con la cantidad de aspectos que unen las identidades de los colectivos (la lengua, los valores, los intereses profesionales).

\section{Objetivos, intenciones y trayectoria del proyecto Mujeres Maestras.}

Mujeres Maestras es una muestra representativa del proyecto homónimo, que se elabora de manera específica para cada espacio en el cual es expuesta. Mujeres Maestras se ha podido ver en Valencia, en Alicante (Universitat d'Alacant), en Tarragona (Universitat Rovira i Virgili), en Bruselas (Sala Espace Atrium del Parlamento Europeo), en Santiago de Chile (Museo Artequín), en Montevideo (Espacio Cultural Al Pie de la Muralla) y en otros lugares, durante los últimos años. En cada uno de estos espacios se contó con los dibujos del alumnado de centros próximos al lugar donde se montaba la exposición. Con ello se consigue:

- Integrar en los colegios de la zona en un montaje expositivo

- Favorecer una mejor conexión entre la sala de exposiciones y los centros educativos

- Valorar el trabajo de aquellas maestras que trabajan cerca de un determinado espacio cultural

- Ofrecer a las maestras una actividad que tendrá repercusiones en el exterior de las aulas y el centro educativo

- Acercar a niños y niñas al arte, mostrando sus producciones

- Atraer a públicos diversos y diferentes, en su mayoría nuevos, hacia una sala de exposiciones: padres, abuelos, amigos y familiares del alumnado, quienes se acercan para ver los dibujos de sus conocidos.

Pensamos que con estas iniciativas conseguimos involucrar de manera participativa tanto a las educadoras como al alumnado, y también a sus correspondientes familias, en una actividad de cariz cultural y artístico. 

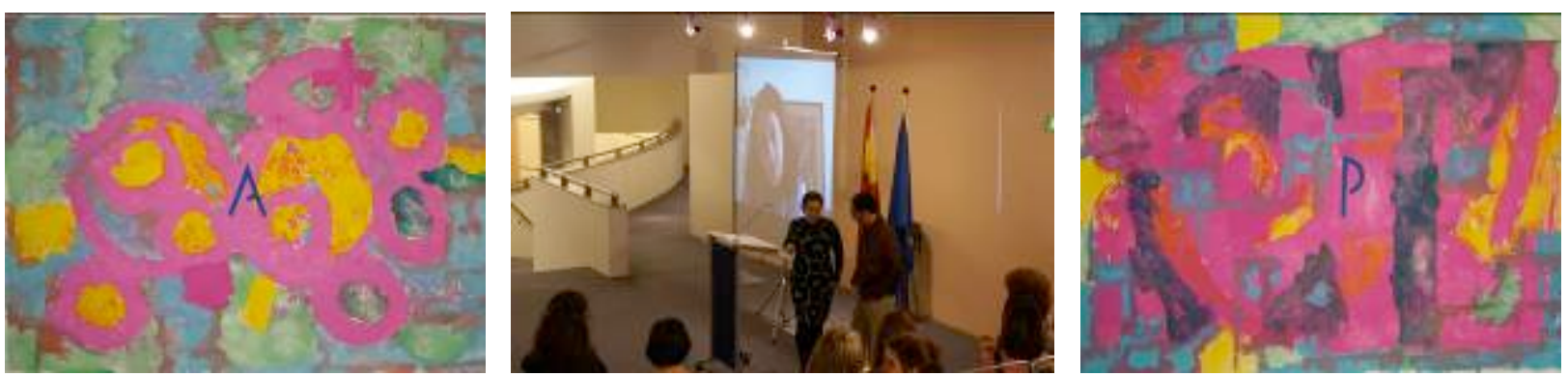

Ilustraciones 1, 2 y 3. A la izquierda la pintura "A" de la Serie Alfabeto de las Maestras de Europa, a la derecha la pintura "P" de la misma serie. En el centro una imagen de la presentación de la exposición “Mujeres Maestras de Europa” en la Sala Espace Atrium del Parlamento Europeo en Bruselas.

El uso de historias de vida dentro de la investigación y la formación es parte de un movimiento más general que se inició en la década de 1980 en el que se daba cita la crítica al positivismo y el desarrollo de la investigación cualitativa, tanto en sus aspectos descriptivos y comprensivos como en las cuestiones de investigación, acción y formación. A partir de entonces el docente es considerado como una parte esencial para analizar y evaluar la calidad de la práctica profesional educativa. El mensaje esencial del viraje metodológico de los años 1980 consistía en el reconocimiento de la dignidad epistemológica y social de las relaciones humanas concretas para la construcción del mundo. Dicha construcción mundo requiere un self activo, creativo y capaz de construir nuevos mundos en colaboración. Las teorías de la construcción social de la realidad se instalan ahora en el lugar que antes había ocupado el funcionalismo. El self tiene un origen social y se define como un conjunto de relaciones: el otro no es un obstáculo para el proyecto de sí, sino una de sus condiciones. Más que la propia identidad, interesa el proceso de su formación y construcción en relación con el otro y basado en el reconocimiento mutuo. El conocimiento es siempre conocimiento de uno mismo e inseparable de la construcción de una relación; se reconoce en la implicación en una relación que se lleva a cabo desde la acción en el tiempo. Por ello, la comprensión de una persona o una comunidad solo es posible cuando es contada, relatada. En el campo de la educación y de la formación de formadores, las historias de vida escenifican un papel de resistencia y de alternativa, con la intención de evitar el uso instrumental de la relación entre formación y trabajo. En el mundo de la escuela y del profesorado el uso de las historias de vida se asocia al reconocimiento de la importancia de la formación de la persona y de la experiencia individual y colectiva de todos los días para la construcción del conocimiento profesional pertinente. Siguiendo esta línea argumental impulsada por Fernando Hernández (Hernández, Sancho y Rivas, 2011), quisiera recalcar que al acercarme a las vidas de las maestras he podido comprobar cómo el sufrimiento y los conflictos (internos y externos) del profesorado emergen de una vulnerabilidad psicológica y social que los profesores desconocían como grupo y como individuos.

Con este trabajo no solamente se establece un criterio de acercamiento hacia el colectivo del profesorado, sino que también se intenta mejorar la práctica docente de un profesor de educación artística, al tiempo que explora las opiniones de mujeres maestras de varios países de Iberoamérica, en este caso Colombia, Ecuador y Perú. Esta investigación artística procura abrir nuevos planteamientos de implicación profesional y personal, al tiempo que se reivindica el papel social de las educadoras. Para realizar la investigación se tienen en cuenta los resultados obtenidos a partir de las entrevistas personales, siempre realizadas por el propio investigador. En base a las narrativas personales se desea conocer mejor la realidad de estas personas, pero también contrastar las diferentes realidades nacionales en todo aquello referido al papel de las docentes en cada entramado social. Gracias a esta iniciativa, quien investiga (también docente en ejercicio) consigue adentrarse en su propio papel como educador mediante un mayor conocimiento de las docentes (la gran mayoría son mujeres). Se trata así mismo de situar a cada maestra en el papel de "modelo" a tener en cuenta. La propuesta acerca la realidad de la escuela a las salas de exposición de diferentes museos que han participado en esta propuesta artística y educativa.

Al acercarme a las vidas de estas maestras no puedo evitar revisar mi propia experiencia vivida, recuperando tres décadas como profesor universitario de educación artística, y en este caso formador de futuras maestras durante todo ese tiempo. Si bien me formé como grabador en los estudios de Bellas Artes y como intérprete en el Conservatorio Superior de Música, amplié mis estudios con la carrera universitaria de Comunicación Audiovisual, lo cual revirtió directamente en mi percepción de la docencia, algo que siempre ejercí. Creo que de la formación musical resta una gran atracción por la idea de los ritmos, algo que me lleva a marcar las pautas de mis clases o de las redacciones de los textos que escribo. Da mi formación como grabador conservo un gran apego a la idea de las series, y puede que sea por ello que siempre utilizo 21 elementos en mis trabajos artísticos y de proyección educativa. Defendí mi tesis doctoral en el año 1992 investigando sobre la creatividad de los artistas que supieron diseñar letras y anuncios para revistas durante la década de 1950, en pleno periodo de autarquía franquista, uno de los momentos más oscuros de la dictadura española. Yo también me muevo actualmente en territorios resbaladizos, ya que la relación entre alumnado y profesorado ha cambiado, y mucho, en los últimos años, pero me apasionan los retos, y en ello estoy, intentando redescubrirme en cada nueva acción pedagógica que llevo a cabo. Siempre me interesaron las coyunturas sociales, y mi deriva de análisis tiene bastante de antropológica, incidiendo en 
perspectivas sociológicas, y contando siempre con el apoyo de los estudios semióticos. Ya en mi tesis doctoral utilicé las entrevistas como eje de recogida de datos, en un sentido casi etnográfico. De aquellas entrevistas pude extraer mucha información válida para mi tesis y, además, pude montar un mediometraje audiovisual que tuvo repercusión por su esquema innovador. Ahora que reviso aquellas tentativas me doy cuenta del aporte que significaron, y que demostrando una clara vocación por acercarme a lo que actualmente definimos como historias de vida. Ya en mis primeros trabajos de investigación se defendía este tipo de estrategias. Es fundamental contar con la voz de las personas implicadas cuando se revisa un tema en concreto o un periodo histórico. Esa transmisión de informaciones y sentimientos es posible cuando las entrevistas son registradas en directo por parte del propio entrevistador. Yo siempre las he grabado en video, lo cual me permite revisarlas comprobando, además de las palabras, los gestos y las modulaciones del lenguaje de las personas entrevistadas. También en el proyecto Mujeres Maestras las entrevistas se registran en video. Cuando investigo cuestiones como la construcción colaborativa del conocimiento, la práctica docente o a la creación artística, mi interés me lleva a acercarme a las personas, a entrevistarlas y conocerlas. Puede que estas directrices estén vinculadas al hecho de que nuestro trabajo docente siempre estuvo directamente vinculado al trato personal con el alumnado y el profesorado. Combinamos aspectos relacionados con la comunicación y con la educación. La retórica es uno de nuestros campos de batalla.
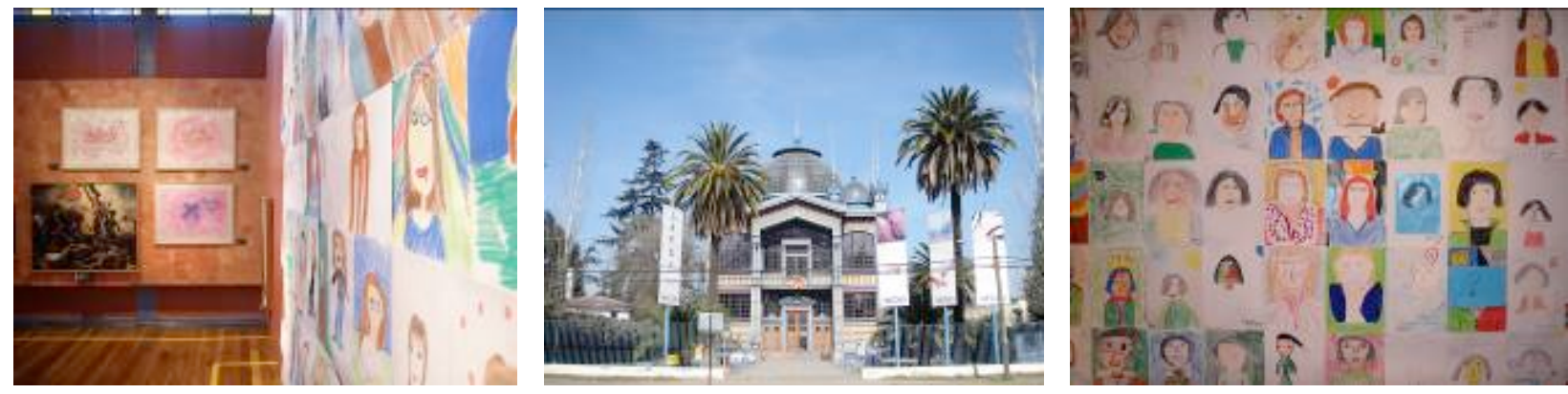

llustraciones 4, 5 y 6. A la izquierda aspecto de la exposición Mujeres Maestras de Chile donde se combinan los trabajos del artista con dibujos infantiles. A la derecha mural con dibujos del alumnado dedicados a sus maestras. En el centro el impresionante edificio del Museo Artequín, situado en la Quinta Normal de Santiago de Chile, que fue Pabellón Nacional en la Exposición Universal de París de 1889.

\section{Desarrollo de la propuesta actual en tres países de Iberoamérica.}

En estos momentos se están preparando las exposiciones de Mujeres Maestras para presentarlas en Lima, Medellín y Cuenca. Cada una de las propuestas está en una fase diferente, por eso me animo a presentarlas como tres procesos creativos que van progresando al unísono, pero con ritmos diversos. Mi conocimiento sobre las realidades de los tres países en los que se va a exponer el proyecto dentro de pocos meses parte de visiones muy diferentes. En el caso de Colombia, la relación con el mundo universitario de este país viene de lejos, ya que fui el promotor del primer convenio de colaboración entre la Universitat de València y la Universidad Nacional de Colombia, lo cual ocurría en 1993. Desde entonces se han sucedido las visitas a este país exuberante, habitualmente dirigidas a observar e investigar la situación de los museos en su proyección educativa. Esto ha permitido que conociese a muchas personas que se dedican a la educación, tanto en entornos formales como informales (Huerta y Alonso-Sanz, 2017). Fue en 2010 cuando inicié los preparativos de la muestra dedicada a este país lleno de contrastes y efervescencias, un territorio que comunica dos océanos y donde las montañas conservan todavía el último glaciar de los Andes. En este territorio tan impregnado de religiosidad y de naturaleza pletórica, las opiniones de las maestras, recogidas en tres períodos distintos, me llevaron a zonas de guerrilla como Rio Sucio, a lugares marginales de Bogotá, a la zona cafetera de Manizales, y por supuesto a una de las ciudades más fascinantes del país: Medellín. Comprobé que incluso en los colegios públicos son habituales las figuras religiosas, decorando pasillos o zonas de reunión.
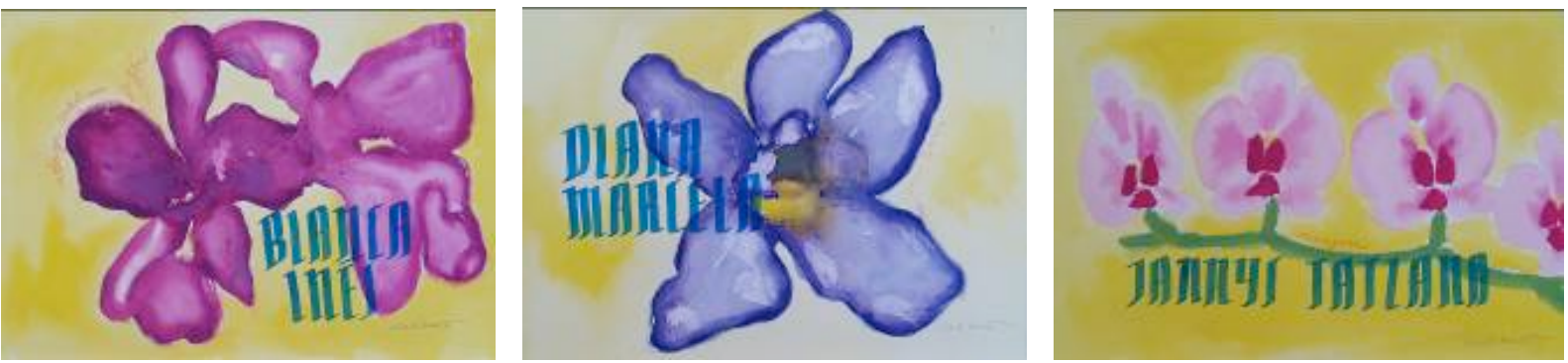

Ilustraciones 7, 8 y 9. Tres ejemplos de la serie Mujeres Maestras de Colombia. Cada maestra viene representada por una orquídea, la flor nacional del país. 
Desde el primer momento quise incorporar a la serie Mujeres Maestras de Colombia una relación evidente con la naturaleza, un vínculo que se mantiene muy vivo en este país repleto de selva y vegetación. La orquídea se revela como todo un símbolo patrio, y es un buen ejemplo de la diversidad, un hecho palpable en esta geografía de la abundancia. Existen miles de orquídeas diferentes. Otro aspecto que siempre me interesó del vocabulario colombiano fueron los gentilicios, y en este caso la sonoridad de los nombres. Es muy habitual que las mujeres tengan dos nombres. Esta circunstancia, unida al hecho de que la creación de nombres resulta allí mucho más libre y rica que, por ejemplo, en nuestro entorno, hace que el juego sonoro de las combinaciones nos ofrezca ejemplos como Jannys Tatiana, Diana Marcela, Blanca Inés, Ángela Patricia, Beatriz Elena, Claudia Patricia, Cruz Elena, Hilda Clemencia, Marta Rocío, Sandra Milena o Silvana Andrea. Ante este panorama sonoro, modulado y generoso, lo que llama la atención es descubrir nombres tan sencillos como Viviana, Maryory, María, o el tremendamente evocador y poderoso Ensueño. La fértil cosecha de nombres con desbordante sonoridad y el empleo de un símbolo tan arraigado en el imaginario del país como es la orquídea, marcan el registro de esta serie, que está interpretada con colores muy vivos, y de forma muy esencial, solamente un elemento central (ña orquídea) acompañado de un texto en el que leemos el nombre de la maestra a quien representa la obra.
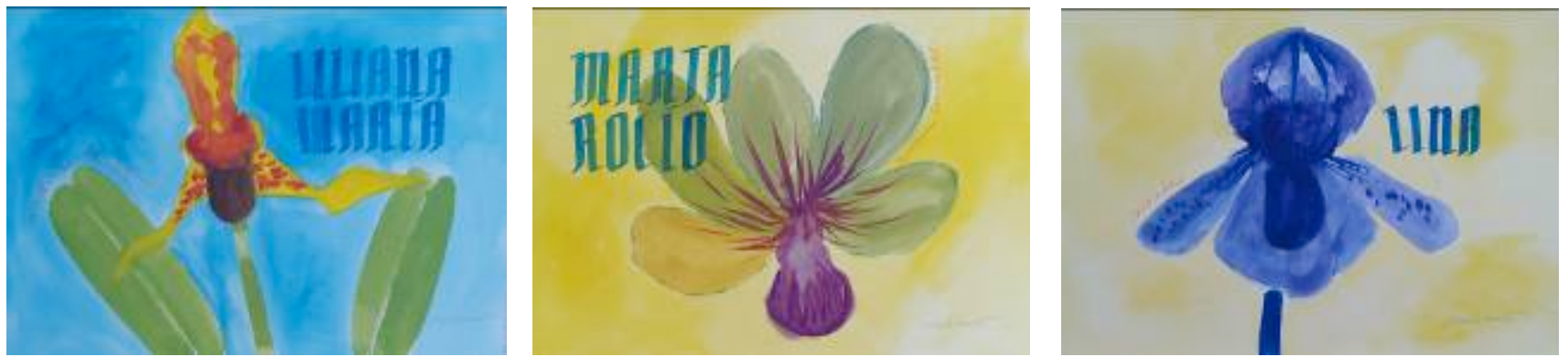

Ilustraciones 10, 11 y 12. Otros tres ejemplos de la serie Mujeres Maestras de Colombia. Ademñas del símbolo de la orquídea, el nombre de la maestra se escribe con una caligrafía diseñada para la serie.

Las entrevistas realizadas a maestras colombianas nos muestran un colectivo implicado y responsable, en el que detectamos una cierta polarización de las actitudes. Frente a las ideas reformadoras de las maestras que proceden de ámbitos laicos, tenemos los testimonios de las que están vinculadas a centros religiosos, por lo que se sienten más cercanas al adoctrinamiento católico. En este sentido, es la voz de las educadoras la que nos acerca al planteamiento más general. En Colombia se vive desde hace décadas una auténtica fiebre de la educación para la paz, tras décadas de conflicto armado y conflicto social. Las maestras han sido un elemento clave en esta reivindicación de la ciudadanía con posturas conciliadoras que en demasiadas ocasiones son silenciadas. El colectivo de docentes ha sido el más agredido durante la contienda, contándose por miles los docentes asesinados. Son los atropellos y las injusticias de un sistema perverso que canaliza hacia los docentes buena parte de su agresividad y violencia. No puedo dejar de emocionarme al escuchar las voces de las Mujeres Maestras que han sufrido el conflicto en su propia piel. Nos dice Beatriz: "En realidad para mí esto ha sido una experiencia de vida. Soy maestra y más me gusta llamarlo acompañante. Somos acompañantes en el proceso de formación de personas. Soy feliz y me siento realizada como ser humano. Es cierto que ayudar al otro me hace crecer a mí. He crecido como persona gracias a las personas que me han rodeado como estudiantes, ellos me han dado la energía para querer lo que hago de manera pasional". El término pasión es habitual en la conversación con las maestras que proceden de ámbitos geográficos próximos al Caribe. Liliana reconoce en su forma de expresarse una gran carga de ilusión: "El ambiente del colegio y los padres contribuyen mucho a que se sientan más tranquilos y a mejorar sus posibilidades. Mi labor es de amor a ellos. Mi vocación es de servicio, buscando en la sociedad a personas que desde que son pequeños, desde niños, van a mejorar el mundo. Trabaja en la Unidad Pedagógica, colegio que ha implantado un sistema singular en el panorama bogotano, ya que no son habituales aquí los centros de tendencia innovadora, sino los que tienen una implicación directa con órdenes religiosas.

El trabajo realizado en Colombia para el proyecto Mujeres Maestras ya está preparado para presentarse en el Museo Universitario de la Universidad de Antioquia, en Medellín. Los responsables del museo, tanto desde la dirección como desde la Unidad de Desarrollo Pedagógico, llevan meses preparando esta muestra que, además, reivindica la educación en museos y el contacto con nuevos públicos que nos son habituales en el ámbito universitario (maestras y familiares de los niños que participan con sus dibujos). La inauguración es el día 24 de abril de 2017, y participan como entidades colaboradoras la Facultad de Educación y la Facultad de Bellas Artes de la propia universidad, además de haber implicado a quince colegios de los distritos próximos al campus universitario.

Mientras tanto, el proceso de preparación de la muestra Mujeres Maestras del Perú, prevista para inaugurarse el 15 de septiembre de 2017, está en un momento de máximo esfuerzo, ya que tras haber realizado las entrevistas (entre 2015 y 2016), estamos ahora en el proceso de montaje y edición del audiovisual. Participan mujeres de todas las edades y estratos sociales. Vamos a dedicar nuestros esfuerzos, y en este caso como homenaje emotivo, a una de las mujeres que entrevistamos y que pocos meses después falleció a causa de un cáncer muy agresivo que nos dejó sin la maestra Rita Carrillo Montenegro. Rita es un ejemplo de mujer implicada, 
valiente, muy rebelde y profundamente comprometida con su ideología, feminista y transgresora. Hemos podido entrevistar también a Madezha Cepeda, una docente invidente que lleva años trabajando por aumentar las posibilidades de los niños y las niñas con diversidad funcional. Junto a ellas, disponemos de los testimonios de Rosana Elizabeth Falcón Mendoza, Rosa Ledesma, Luzmila Mendívil Trelles, Vannia Stefany Mestranza Calderón (estudiante), Cecilia Milagros Limache Muñante, Nadia Romaní, Juanita Shedan Manga, Elsa Tueros Way, Elena Valdiviezo Gainza, María Felipa Valdivia, Mirna Palacios Llanos, Zoila Verónica Tuñoque, Sheila Vanessa Chuquiyaure, Cleyla Reimundo Ramos, Yessie Maribel Fabién Picón, Maribel Cormack Lynch, Cecilia Noriega Ludwick o Jesica Kohatsu. Procedentes de colegios y centros educativos muy diferentes, nos ofrecen una muestra variada y rica de la enorme diversidad que presenta un país tan complejo y seductor como el Perú.
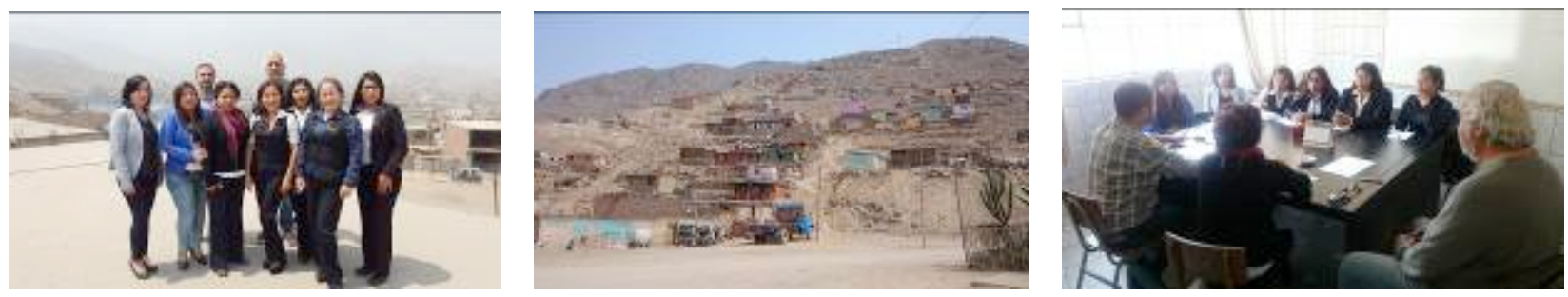

Ilustraciones 13, 14 y 15. Preparativos de las entrevistas para la serie Mujeres Maestras del Perú. Las maestras entrevistadas en este caso pertenecen al colegio de Jicamarca, localidad cercana a Lima, con asentamientos humanos en unas condiciones de verdadera dificultad.

En los trabajos gráficos con los que se representará a las docentes peruanas se están incluyendo elementos que tienen que ver con la cocina y con los tejidos, dos características que visibilizan con determinación el saber milenario de este país, riquísimo por sus culturas precolombinas, y muy variado por su estratégica situación geográfica. También se incorpora un alfabeto diseñado para la ocasión, con el que se dibujarán los nombres de las protagonistas, en un ejercicio caligráfico que supone un retrato de cada una de ellas. Lima es una ciudad muy gris la mayor parte del año. Sin embargo, a diferencia de los que ocurrió en la serie dedicada a las mujeres del Uruguay, donde el gris imperaba, aquí serán los colores vivos la paleta con la que se compondrán las 21 piezas del conjunto.

En lo referido a la futura serie Mujeres Maestras de Ecuador, cabe decir que está en la fase más expectante: el inicio del inicio. Siento fascinación por este país, y durante el mes de agosto de 2017 se realizarán las entrevistas a las maestras ecuatorianas que nos acompañarán en este nuevo reto. La ciudad de Cuenca posee un indudable atractivo patrimonial, del mismo modo que Quito llama la atención por su halo misterioso repleto de reminiscencias precolombinas. Allí se están incubando los preparativos, estableciendo contactos con centros educativos y maestras de todos los estratos sociales y de todas las edades y condiciones. Se trata de volver a encender el deseo por conocer y representar, por vivir y comprender, por acercarse a los universos sugeridos por los relatos de las mujeres maestras. Aquí empieza todo.

\section{Conclusiones.}

La metodología cualitativa de los estudios de caso junto con la investigación basada en las artes y la cultura visual nos sirven para acercarnos a las identidades docentes del panorama iberoamericano. El proyecto Mujeres Maestras ha recorrido algunos países, y en este momento se preparan exposiciones para Medellín, Lima y Cuenca, ciudades de Colombia, Perú y Ecuador en las que se está desarrollando este proyecto de investigación en Educación Artística. La vertiente antropológica que adquiere el proceso nos lleva a descubrir la coyuntura social, económica, laboral y personal de cada una de estas mujeres. Al implicar a los museos y los centros educativos desarrollamos estrategias de acercamiento entre estos entornos aptos para la acción pedagógica. Nuestro homenaje supone un reconocimiento de la labor de este colectivo tan poco visibilizado y que, sin embargo, resulta tan importante en nuestras vidas: el de las mujeres maestras.

\section{FUENTES REFERENCIALES.}

HERNÁNDEZ, Fernando, SANCHO, Juana M. y RIVAS, José Ignacio, (coord.). Historias de vida en educación: Biografías en contexto. Barcelona: Universitat de Barcelona, 2011. Depósito Digital UB. http://hdl.handle.net/2445/15323

HUERTA, Ricard. Un Proyecto de investigación en educación artística: aspectos identitarios de las maestras chilenas. Pulso Revista de Educación, 2010, 33, 31-59. ISSN 1577-0338

HUERTA, Ricard. Mujeres Maestras. Identidades docentes en Iberoamérica. 1a edición. Barcelona: Graó, 2012. ISBN 978849980411 
III CONGRESO INTERNACIONAL DE INVESTIGACIÓN EN ARTES VISUALES :: ANIAV 2017 :: GLOCAL [codificar, mediar, transformar, vivir] http://dx.doi.org/10.4995/ANIAV.2017.5085

HUERTA, Ricard. Mujeres Maestras de Perú: investigar en educación artística transitando entornos formales e informales. Revista Gearte, Porto Alegre, 2016, 3, 3, 427-443. ISSN 2357-9854

HUERTA, Ricard y ALONSO-SANZ, Amparo. Entornos informales para educar en artes. 1ạ edición. Valencia: PUV, 2017. ISBN 9788491340010

RIVAS, José Ignacio, HERNÁNDEZ, Fernando, SANCHO, Juana M. y NÚÑEZ, Claudio (coord.). Historias de vida en educación: Sujeto, Diálogo, Experiencia. Barcelona: Universitat de Barcelona, 2012. Depósito Digital UB. http://hdl.handle.net/2445/32345 